\title{
Cerebrospinal fluid biomarkers for Alzheimer's and vascular disease vary by age, gender, and $A P O E$ genotype in cognitively normal adults
}

\author{
Ge Li ${ }^{1,2,3^{*}}$ D, Jane B. Shofer ${ }^{2}$, Eric C. Petrie ${ }^{2,3}$, Chang-En Yu', Charles W. Wilkinson ${ }^{1,2}$, Dianne P. Figlewicz ${ }^{2,4}$, \\ Andrew Shutes-David ${ }^{1,3}$, Jing Zhang ${ }^{5}$, Thomas J. Montine ${ }^{6}$, Murray A. Raskind ${ }^{2,3}$, Joseph F. Quinn ${ }^{7,8}$, \\ Douglas R. Galasko ${ }^{9}$ and Elaine R. Peskind ${ }^{2,3}$
}

\begin{abstract}
Background: This study sought to evaluate gender and APOE genotype-related differences in the concentrations of cerebrospinal fluid (CSF) biomarkers for Alzheimer's disease (AD) and cerebrovascular injury across the life span of cognitively normal adults.

Methods: CSF amyloid beta $_{1-42}\left(A \beta_{42}\right)$, phospho-tau-181 ( $p$-tau $\left.{ }_{181}\right)$, and total tau were measured in 331 participants who were between the ages of 21 and 100. CSF E-selectin and vascular cell adhesion protein 1 (VCAM1) were measured in 249 participants who were between the ages of 50 and 100.

Results: CSF total tau and $p$-tau ${ }_{181}$ increased with age over the adult life span $(p<0.01)$ with no gender differences in those increases. CSF $A \beta_{42}$ concentration varied according to age, gender, and APOE genotype (interaction of age $\times$ gender $\times \varepsilon 4, p=0.047)$. CSF VCAM1, but not E-selectin, increased with age $(p<0.01)$, but both were elevated in men compared to women $(p<0.01)$.

Conclusions: Female APOE- $\varepsilon 4$ carriers appear at higher risk for AD after age 50. In contrast, men may experience a relatively higher rate of cerebrovascular injury in middle and early old age.
\end{abstract}

Keywords: Alzheimer's disease, Cerebrovascular disease, Cerebrospinal fluid, Biomarkers, Age, Gender, APOE genotype

\section{Background}

The reasons for gender differences in the risk of developing Alzheimer's disease (AD) or other dementias remain unclear. Epidemiological studies have shown that the incidence of AD increases steeply with age in both men and women, but the rate of increase diverges between genders in later ages: after age 90, the incidence levels off in men, but it continues to increase in women [1-3]. One possibility is that men have higher mortality rates from cardiovascular disease than women. Indeed, the selective survival of

\footnotetext{
* Correspondence: gli@uw.edu

${ }^{1}$ Geriatric Research, Education, and Clinical Center, VA Puget Sound Health Care System, 1660 S. Columbian Way, Seattle, WA 98108, USA

${ }^{2}$ Department of Psychiatry and Behavioral Sciences, University of Washington, 1959 NE Pacific St, Box 356560, Seattle, WA 98195, USA Full list of author information is available at the end of the article
}

men with a healthier cardiovascular risk profile and lower propensity to dementia may partly explain the relatively higher risk for dementia and AD that is observed in women versus men in older ages [4].

Another potential mechanism for the increased incidence of $\mathrm{AD}$ in women over the age of 80 is the loss, after menopause, of the neuroprotective effect of estrogens $[5,6]$. The challenge in understanding the potential role of estrogen in $\mathrm{AD}$ is the long lag time between the drastic hormonal changes and clinical manifestations of $\mathrm{AD}$. The critical period of hormonal changes in women is around age 50, which is $20-30$ years prior to the clinical manifestation of dementia. Recent studies have shown that cerebrospinal fluid (CSF) biomarkers of neurodegenerative processes in $\mathrm{AD}$ (e.g., concentrations of amyloid beta ${ }_{1-42}\left(\mathrm{~A} \beta_{42}\right)$, total tau, phospho-tau-181 (p-tau 181 ), and the tau $/ \mathrm{A} \beta_{42}$ ratio) 
may reflect underlying $\mathrm{AD}$ pathophysiology long before changes in memory and cognition are clinically detectable $[7,8]$. Decreases in the concentration of CSF $A \beta_{42}$ (which correspond to increased deposition of amyloid in the brain [9]), increased p-tau ${ }_{181}$, and increased total tau occur up to 25 years prior to clinical expression [10]. Recently, we have shown that CSF E-selectin is a candidate biomarker for cerebrovascular injury [11]. E-selectin is an adhesion molecule produced by endothelial cells [12], usually after vascular injury, and is induced by cytokines [13, 14]. When released, E-selectin recruits leukocytes to sites of inflammation or injury [12], thereby contributing to cerebrovascular disease [13, 14]. Using these kinds of biomarkers as markers for preclinical $\mathrm{AD}$ or cerebrovascular injury, we may be able to bring our understanding and recognition of pathological processes closer to the time in life at which hormonal changes occur. In addition, each specific biomarker enables us to identify specific pathological processes of $\mathrm{AD}$ and other conditions, such as cerebrovascular disease. These pathological processes are commonly comorbid in older persons, affect cognitive function in different ways, and are difficult to tease apart clinically.

In the present study, we examined age-related gender differences in CSF biomarkers for $\mathrm{AD}\left(\mathrm{A} \beta_{42}, \mathrm{p}\right.$-tau ${ }_{181}$, and total tau) and vascular injury (E-selectin and vascular cell adhesion protein 1 (VCAM1)) across the life span of cognitively normal adults. We also examined how these differences varied by apolipoprotein $\mathrm{E}(A P O E)$ genotype. The findings from this study are important in elucidating various biological pathways that may play a role in the development of dementia and that may thereby inform the design of targeted prevention strategies.

\section{Methods}

\section{Participants}

Two cohorts of study participants were initially recruited for this study, one cohort for a biomarker study of $\mathrm{AD}$ and one cohort for a vascular biomarker study. The collection and analysis of CSF AD biomarkers and clinical data in the first cohort were approved by the University of Washington (UW) institutional review board (IRB; under approval numbers 01-8926-V and 01173). This cohort included 331 participants who ranged in age from 21 to 100 and who were enrolled at the UW Alzheimer's Disease Research Center (ADRC) and five collaborating centers, including the University of California at San Diego (UCSD), Oregon Health \& Science University (OHSU), Indiana University, University of Pennsylvania, and University of California at Davis. The collection and analysis of novel vascular biomarkers in the CSF of the second cohort occurred at three of these same institutions under the approval of their respective IRBs (UW 01-8926-V and 01173, UCSD 080012, and OHSU 6845). This cohort included 249 participants who ranged in age from 50 to 100 . There was an overlap of 126 participants between the two cohorts, but these overlapping participants were all age $\geq 50$. Additional file 1: Table S1 compares the characteristics of a subset of participants from the first cohort who are age $\geq 50$ to the participants of the second cohort (who are all age $\geq 50$ ).

All participants from both cohorts provided written informed consent prior to enrollment in the study. All participants also underwent standardized diagnostic evaluation as described in a previous report [15], were medically stable, and had no evidence or history of cognitive or functional decline. Mild cognitive impairments and dementia were ruled out in participants based on extensive neuropsychological testing, collateral information, and clinical diagnosis.

\section{Measurements of CSF biomarkers}

CSF was obtained using 24-gauge Sprotte atraumatic spinal needles; the lumbar puncture procedures have been described elsewhere [16]. All CSF samples were analyzed at the UW ADRC laboratory using $0.5 \mathrm{ml}$ aliquots that had been stored continuously frozen at $-80{ }^{\circ} \mathrm{C}$ in polypropylene cryotubes and that had never previously thawed. The CSF samples were analyzed for $A \beta_{42}$, p$\operatorname{tau}_{181}$, and total tau using multiplex reagents (Luminex; InnoGenetics) according to the manufacturer's instructions and as described previously [17]. CSF E-selectin and VCAM1 were measured using the Human Premixed Multi-Analyte Kit (R\&D Systems, Minneapolis, MN, USA) [18]. Assays were performed following the manufacturer's protocol with slight modifications (http:// www.rndsystems.com/pdf/LXSAH.pdf) using a LiquiChip Luminex $200^{\text {mis }}$ Workstation (Qiagen, Valencia, CA, USA). The APOE (M12529; GenBank) genotype was determined using a restriction digest method [19].

\section{Statistical analysis}

The average difference in CSF biomarker concentration $\left(\mathrm{A} \beta_{42}\right.$, total tau, p-tau ${ }_{181}$, E-selectin, and VCAM1) by gender was examined using linear regression. For these analyses, the CSF biomarker of interest was the dependent variable, and age, gender, and $A P O E$ genotype (i.e., presence versus absence of the $A P O E-\varepsilon 4$ allele) were the independent covariates; age was modeled as a three-degree restricted cubic spline to allow for nonlinear associations between age and CSF biomarker, with knots placed at the 5th, 50th, and 95th percentiles (corresponding to ages 24, 60, and 81 for the CSF AD biomarker cohort and ages 55, 70, and 85 for the CSF vascular biomarker cohort) [20]. The role of gender as an effect modifier in the association between CSF biomarkers and age was tested by adding an age $\times$ gender interaction term to the regression model. The additional role of the $A P O E$ genotype as an effect modifier in the association between CSF biomarkers, age, and gender was 
tested by adding a three-way age $\times$ gender $\times A P O E$ genotype interaction term. Hypothesis testing relating to Eselectin was carried out using log E-selectin to satisfy the homogeneity of variance assumption, and the results were back-transformed to the original units, except where noted.

In instances where gender significantly affected the ageCSF biomarker association, nonparametric bootstrap methods were used to calculate $95 \%$ confidence intervals (CIs) for the mean difference in CSF biomarker concentration by gender across the age span. We selected the bootstrap approach for its ease in estimating CIs from complex models. This bootstrapping method generated 5000 datasets, and on each dataset the regression model for the CSF biomarker of interest was used to estimate a set of agedependent mean differences in CSF biomarker by gender. The adjusted percentile method was then used in these 5000 sets of differences to calculate $95 \%$ CIs for the mean difference in biomarker by gender across the age span [21]. Linear regression was also used to determine the association between CSF vascular biomarkers (the dependent variables) and vascular risk factors (body mass index (BMI), history of diabetes mellitus, and hypertension or coronary artery disease), adjusting for age and gender. BMI and age were both modeled as three-degree restricted cubic splines as stated earlier. The association between CSF E-selectin and CSF VCAM1 was assessed using linear regression with CSF VCAM1 as the dependent variable and CSF E-selectin as the independent variable. Effect modification due to age or gender was assessed by testing the significance of the Eselectin by age or gender interaction term.

R 2.15.2 [22] and the Hmisc and rms packages [23] were used to carry out the regression models, and the boot package [24] was used to perform the bootstraps. Mean changes in biomarkers estimated from the regression models presented in the text are accompanied with 95\% CIs in parentheses.

\section{Results}

The demographic and CSF biomarker characteristics of the participants are presented in Table 1. Male participants in the $\mathrm{AD}$ biomarker cohort had significantly higher levels of education than female participants in the CSF AD biomarker cohort $(p=0.016)$, and male participants in the vascular biomarker cohort had lower MMSE scores than female participants in the vascular biomarker cohort $(p<0.01)$. However, there were no other significant gender differences in mean age, BMI, or $A P O E-\varepsilon 4$ status in either cohort.

\section{Gender differences in CSF AD biomarker concentrations across the life span}

Mean CSF total-tau and $\mathrm{p}$-tau ${ }_{181}$ concentrations were significantly increased $(p<0.01)$ with increasing participant age in both men and women (see Fig. 1a, b). There were no

Table 1 Characteristics of participants by gender

\begin{tabular}{|c|c|c|c|c|}
\hline & \multicolumn{2}{|c|}{ CSF AD biomarker sample } & \multicolumn{2}{|c|}{ CSF vascular biomarker sample } \\
\hline & $\begin{array}{l}\text { Female } \\
(n=178)\end{array}$ & $\begin{array}{l}\text { Male } \\
(n=153)\end{array}$ & $\begin{array}{l}\text { Female } \\
(n=141)\end{array}$ & $\begin{array}{l}\text { Male } \\
(n=108)\end{array}$ \\
\hline Age (years) & $\begin{array}{l}57.5(16.8) \\
(21-100)\end{array}$ & $\begin{array}{l}56.0(19.6) \\
(22-88)\end{array}$ & $\begin{array}{l}70.0(8.5) \\
(50-100)\end{array}$ & $\begin{array}{l}72.1(9.1) \\
(50-90)\end{array}$ \\
\hline BMI $\left(\mathrm{kg} / \mathrm{m}^{2}\right)$ & $\begin{array}{l}25.8(4.3) \\
(18-41)\end{array}$ & $\begin{array}{l}26.4(3.4) \\
(20-37)\end{array}$ & $\begin{array}{l}25.7(4.3) \\
(18-39)\end{array}$ & $\begin{array}{l}26.3(3.0) \\
(20-36)\end{array}$ \\
\hline Education (years) & $\begin{array}{l}15.8(2.5) \\
(10-22)\end{array}$ & $\begin{array}{l}16.5(2.8)^{*} \\
(10-27)\end{array}$ & $\begin{array}{l}15.8(2.5) \\
(9-23)\end{array}$ & $\begin{array}{l}16.2(2.6) \\
(10-25)\end{array}$ \\
\hline MMSE score & $\begin{array}{l}29.3(0.9) \\
(26-30)\end{array}$ & $\begin{array}{l}29.2(1.2) \\
(25-30)\end{array}$ & $\begin{array}{l}29.5(0.9) \\
(25-30)\end{array}$ & $\begin{array}{l}28.8(1.4)^{*} \\
(24-30)\end{array}$ \\
\hline APOE-£4 positive, $n(\%)$ & $67(38)$ & $48(31)$ & 49/136 (36) & $33 / 100(33)$ \\
\hline $\mathrm{A} \beta_{42}(\mathrm{pg} / \mathrm{ml})$ & $\begin{array}{l}331(135) \\
(63-821)\end{array}$ & $\begin{array}{l}323(116) \\
(98-801)\end{array}$ & & \\
\hline Total tau (pg/ml) & $\begin{array}{l}47.9(13.4) \\
(7-91)\end{array}$ & $\begin{array}{l}50.5(15.0) \\
(18-130)\end{array}$ & & \\
\hline $\mathrm{p}-\mathrm{tau}_{181}(\mathrm{pg} / \mathrm{ml})$ & $\begin{array}{l}31.3(8.4) \\
(<7-67)\end{array}$ & $\begin{array}{l}32.6(12.7) \\
(9-107)\end{array}$ & & \\
\hline E-selectin (pg/ml) & & & $\begin{array}{l}42.1(33.2) \\
(1.5-188)\end{array}$ & $\begin{array}{l}60.3(42.1) \\
(1.5-226)\end{array}$ \\
\hline VCAM1 (ng/ml) & & & $\begin{array}{l}115(59) \\
(34-343)\end{array}$ & $\begin{array}{l}147(70) \\
(42-429)\end{array}$ \\
\hline
\end{tabular}

Data presented as mean (standard deviation) (range), unless stated otherwise

$A \beta_{42}$ amyloid beta ${ }_{1-42}, A D$ Alzheimer's disease, APOE apolipoprotein E, BMI body mass index, CSF cerebrospinal fluid, MMSE Mini-Mental State Examination, $p$-tau 181 phospho-tau-181, VCAM1 vascular cell adhesion protein 1

${ }^{*} p<0.05$ for gender difference within each cohort by $t$ test or $x^{2}$ test 

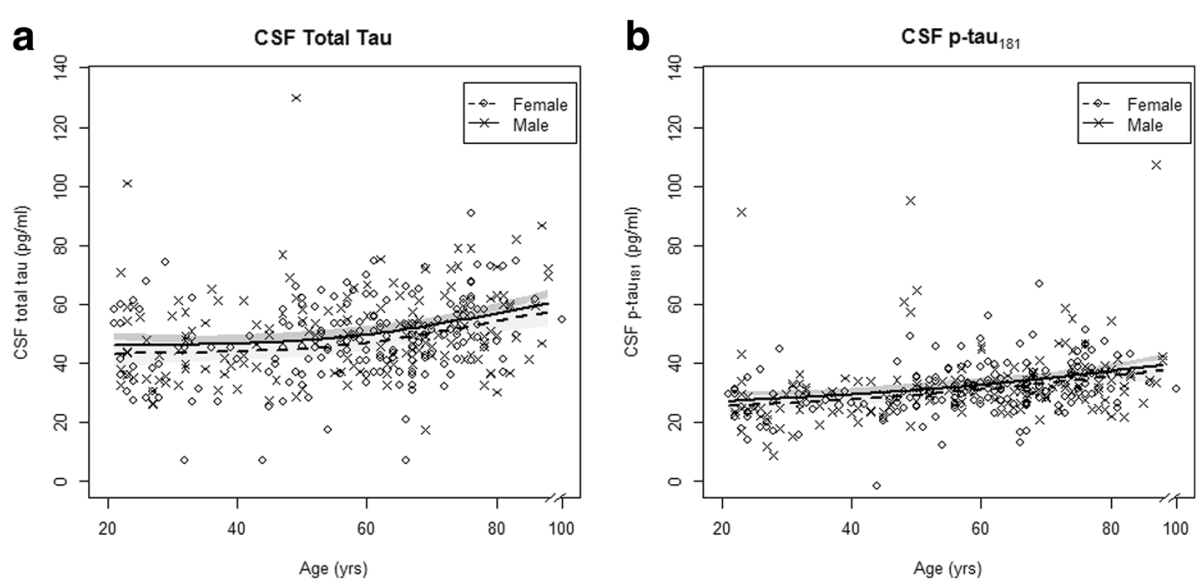

Fig. 1 CSF AD tau biomarkers by age and gender. Scatterplot of CSF total tau (a) and p-tau ${ }_{181}$ (b) vs participant age and predicted means with 95\% Cls from linear regression on gender $\times$ age interaction, adjusted for APOE genotype. CSF cerebrospinal fluid, $p$-tau 181 phospho-tau-181, yrs years

differences in average total tau or $\mathrm{p}$-tau 181 by gender (Table 2). Furthermore, there was no evidence that the increase in total tau or $\mathrm{p}$-tau 181 across age differed by gender (age $\times$ gender interaction, $p \geq 0.43$ ) or that differences in age-adjusted total tau or $\mathrm{p}$ - $\operatorname{tau}_{181}$ by gender were further modified by $A P O E$ genotype (age $\times$ gender $\times A P O E$ genotype interaction, $p \geq 0.16$; Table 2 ).

In contrast to the age-CSF tau relationships, there was a lack of overall association between CSF $A \beta_{42}$ and age or between CSF $A \beta_{42}$ and gender (Table 2, Fig. 2a). The association between CSF $A \beta_{42}$ and age was complex due to the effect modification by gender and $A P O E$ genotype (age $\times$ gender $\times A P O E$ genotype interaction, $p=0.047$ ) and the presence of nonlinear trends in CSF $A \beta_{42}$ across the age span (Fig. 2, Additional file 1: Table S2). Specifically, the age-related and gender-related differences in CSF $\mathrm{A} \beta_{42}$ were dependent on $A P O E$ genotype. In the $\varepsilon 4$ noncarriers, average CSF $A \beta_{42}$ increased monotonically across participant age for females, whereas CSF $A \beta_{42}$ increased up to midlife and then leveled off for males (Fig. 2b). In the $\varepsilon 4$ carriers, average CSF $A \beta_{42}$ decreased gradually across participant age in males up to midlife and then leveled off. By contrast, in females, average CSF $A \beta_{42}$ remained relatively high through age 50 and then had a rapid decline after age 50 (Fig. 2c). For example, mean decrease in CSF $\mathrm{A} \beta_{42}$ from age 50 to age 75 was $103 \mathrm{pg} / \mathrm{ml}$ in female $\varepsilon 4$ carriers but only $9 \mathrm{pg} / \mathrm{ml}$ for male $\varepsilon 4$ carriers. The magnitudes of predicted mean change in CSF $\mathrm{A} \beta_{42}$ along different age intervals and stratified by gender and $A P O E$ are presented in Additional file 1: Table S2.

\section{Gender differences in CSF vascular biomarker concentrations across the life span}

Mean CSF E-selectin concentration was not correlated with participant age $(p=0.47$; Table 1 , Fig. $3 \mathrm{a})$, whereas mean VCAM1 concentration increased with participant age $(p<0.01$; Table 1 , Fig. $3 \mathrm{~b})$. Males had higher mean CSF E-selectin and VCAM1 levels than females $(p<0.01$; Table 1). Furthermore, gender was a significant effect modifier in the association between E-selectin and participant age (age $\times$ gender interaction, $p=0.03$; Table 2, Fig. 3a, c) such that males had higher mean E-selectin

Table 2 Changes in CSF biomarkers by age and gender and interactive effects predicted from regression models

\begin{tabular}{|c|c|c|c|c|}
\hline & \multirow[b]{2}{*}{ Age difference $^{b}$} & \multirow[b]{2}{*}{ Gender difference $^{c}$} & \multicolumn{2}{|c|}{$p$ value for interaction term ${ }^{a}$} \\
\hline & & & Age $\times$ gender & Age $\times$ gender $\times \varepsilon 4$ \\
\hline$A \beta_{42}(p g / m l)$ & $37(-2,76), 0.09$ & $-5(-32,23), 0.75$ & 0.51 & 0.047 \\
\hline Total tau (pg/ml) & $8.9(4.7,13.1),<0.01$ & $2.7(-0.3,5.7), 0.08$ & 0.43 & 0.21 \\
\hline $\mathrm{p}-\operatorname{tau}_{181}(\mathrm{pg} / \mathrm{ml})$ & $8.5(5.4,11.6),<0.01$ & $1.6(-0.6,3.8), 0.15$ & 0.85 & 0.16 \\
\hline E-selectin $(\mathrm{pg} / \mathrm{ml})^{\mathrm{d}}$ & $13(-6,43), 0.47$ & $20(10,33),<0.01$ & 0.04 & 0.65 \\
\hline VCAM1 (ng/dl) & $66(30,102),<0.01$ & $24(8,39),<0.01$ & 0.34 & 0.64 \\
\hline
\end{tabular}

$A \beta_{42}$ amyloid beta $_{1-42}, A P O E$ apolipoprotein $\mathrm{E}$, CSF cerebrospinal fluid, $p$-tau 181 phospho-tau-181, VCAM1 vascular cell adhesion protein 1

${ }^{a}$ From linear regression models of CSF biomarker on age $\times$ gender interaction adjusted for $A P O E-\varepsilon 4$ status or on age $\times$ gender $\times A P O E-\varepsilon 4$ status interaction

${ }^{b}$ Age difference: mean difference ( $95 \%$ confidence interval) and $p$ value in CSF A $\beta_{42}$, total tau, and $p$-tau 181 for an increase in participant age from 25 to 75 years; and mean difference and $p$ value in E-selectin and VCAM1 for an increase in participant age from 50 to 75 years

'Gender difference: mean difference (95\% confidence interval) and $p$ value in concentration of CSF biomarker in males minus females

${ }^{\mathrm{d}}$ Hypothesis testing carried out on log E-selectin, with results presented back-transformed into the original scale 

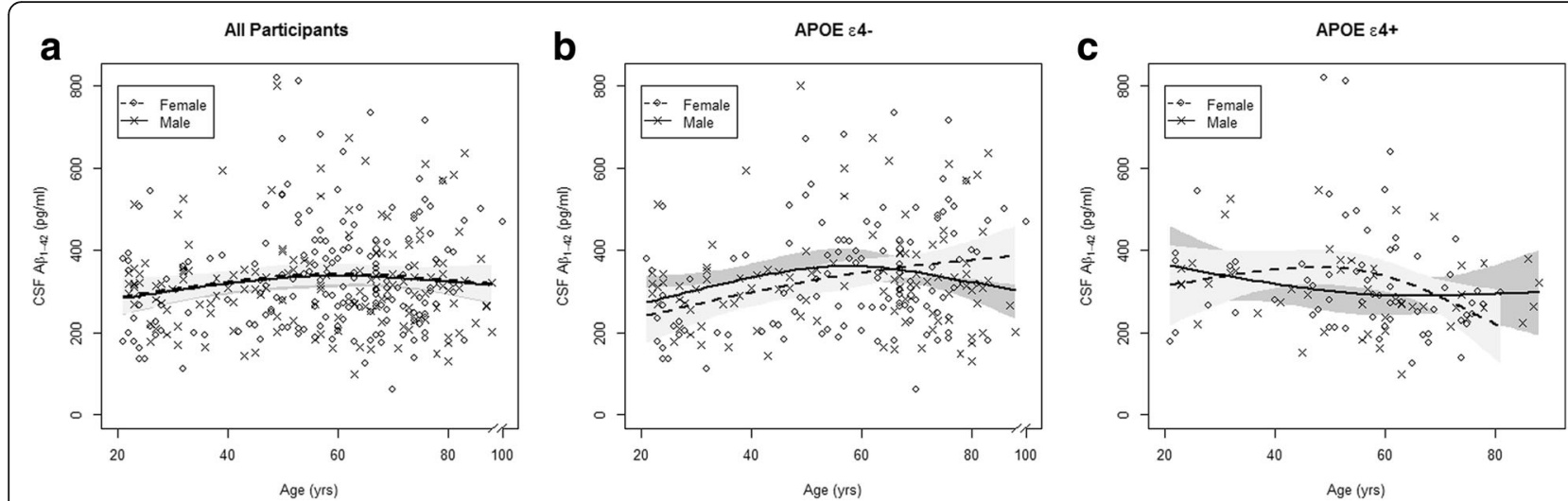

Fig. 2 CSF A $\beta_{42}$ by age and gender and stratified by APOE genotype. Scatterplot of CSF A $\beta_{42}$ vs participant age and predicted means with $95 \%$ Cls predicted from linear regression on gender $\times$ age interaction adjusted for APOE- $\varepsilon 4$ status (a), and stratified by APOE- 44 negative (b) and positive (c) from linear regression on gender by age $\times A P O E-\varepsilon 4$ interaction. $A \beta_{42}$ amyloid beta ${ }_{1-42}, A P O E$ apolipoprotein $E$, CSF cerebrospinal fluid, yrs years
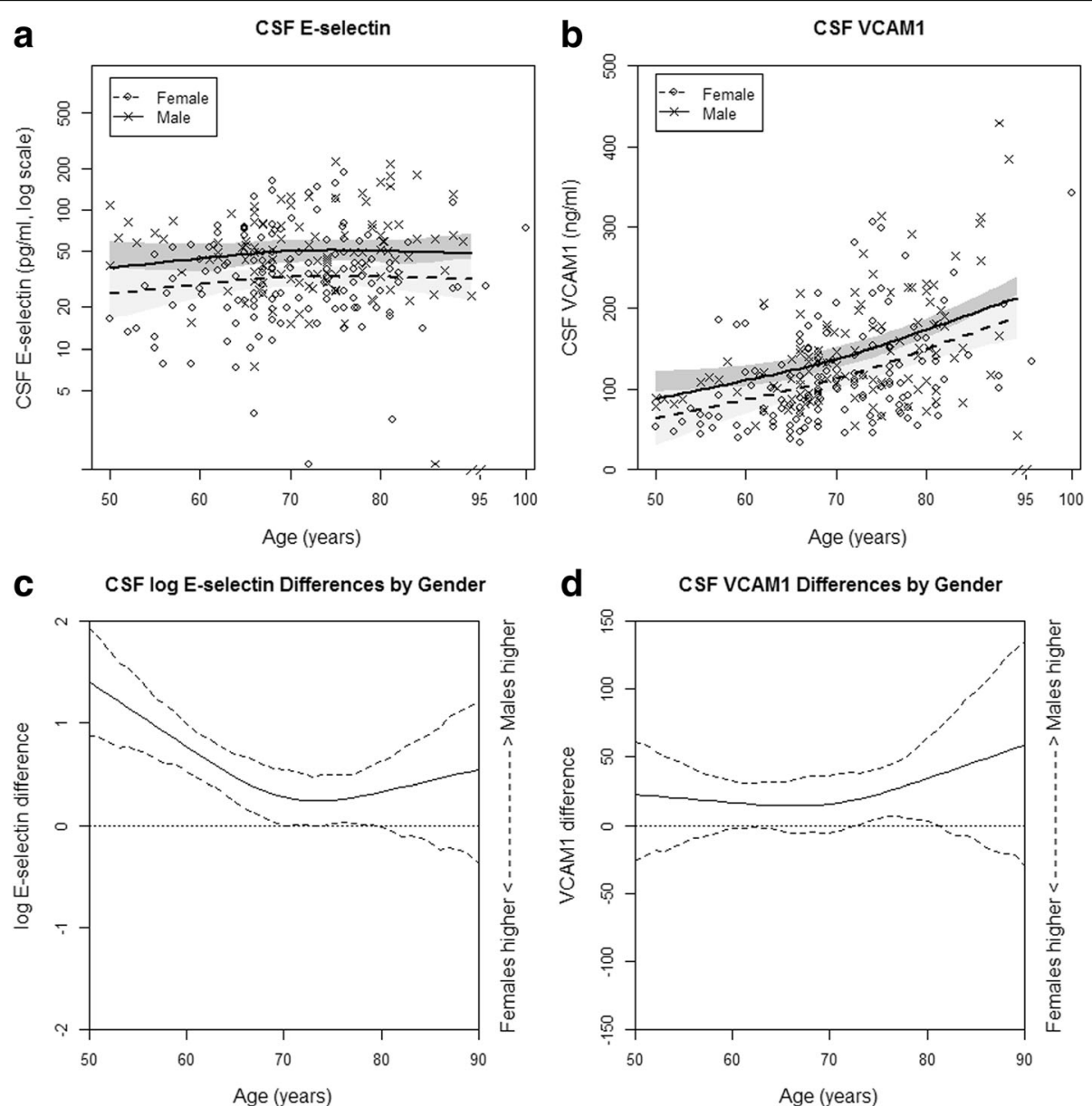

Fig. 3 CSF vascular biomarkers by age and gender. Scatterplot of CSF E-selectin, log scale (a) and VCAM1 (b) vs participant age and predicted means with 95\% Cls, and mean male minus female difference in log E-selectin (c) and VCAM1 (d) with 95\% Cls predicted from linear regression on gender $\times$ age interaction, adjusted for APOE genotype. CSF cerebrospinal fluid, VCAM1 vascular cell adhesion protein 1 
than females at earlier participant ages (i.e., approximately age 50-70) but not at older ages. There was no effect modification of $A P O E$ genotype on the age-dependent gender difference in E-selectin (age $\times$ gender $\times A P O E-\varepsilon 4$ status, $p=0.65)$, and there was no evidence that gender modified the relationship between VCAM1 and age ( $p=$ 0.35 ; Fig. 3b, d) or that age-dependent gender differences in VCAM1 were modified by $A P O E$ genotype (age $\times$ gender $\times A P O E-\varepsilon 4$ interaction, $p=0.64$ ). As a sensitivity analysis, we repeated the previous analyses in participants who took part in both the AD and vascular biomarker study $(n=126)$. In these analyses, males still had higher mean E-selectin levels than females $(p=0.052)$. The effect modification pattern of gender on the age-E-selectin relationship was also similar, but the age $\times$ gender interaction was no longer statistically significant $(p=0.13)$. As in our primary analysis, males also had higher mean VCAM1 levels than females $(p=0.02)$.

\section{Relationship of CSF E-selectin or VCAM1 with vascular risk factors}

There were 55 participants with hypertension, 12 with diabetes mellitus, and 11 with coronary artery disease in the CSF vascular subsample. CSF E-selectin concentration was correlated positively with BMI after adjusting for age and gender $(p<0.01)$. Mean CSF E-selectin was higher in participants with diabetes mellitus by $19 \mathrm{pg} / \mathrm{ml}$ (95\% CI: 2,50 ) but the relationship did not reach statistical significance after adjusting for age and gender $(p=0.08)$. VCAM1 was not significantly correlated with BMI $(p=$ 0.71 ) but was elevated in participants with diabetes mellitus by $61 \mathrm{ng} / \mathrm{ml}(95 \%$ CI: $28,95, p<0.01)$. There was no significant association between E-selectin or VCAM1 and history of hypertension or coronary artery disease $(p>$ $0.05)$. CSF E-selection and VCAM1 was positively correlated such that $r=0.23\left(r^{2}=0.05\right.$, linear regression $p<$ $0.01)$. This correlation was not modified by age or gender (CSF E-selectin by age or gender interactions $p>0.67$ ).

\section{Discussion}

In this study of cognitively normal adults, we found that the CSF AD biomarkers total tau and $\mathrm{p}$-tau ${ }_{181}$ increased with participant age over the adult life span (i.e., ages 20-100) with no significant gender or $A P O E$ genotype differences in those increases. In contrast, CSF $A \beta_{42}$ concentration varied according to age, gender, and $A P O E$ genotype.

The nonlinear relationship between age and CSF A $\beta_{42}$ is likely because our sample includes both participants who are experiencing normal aging as well as participants over the age of 50 who may have preclinical AD. Although the process of brain amyloid metabolism is not entirely clear in normal aging, during the early stages of $A D$ brain $A \beta_{42}$ starts to aggregate, causing a "sink" effect characterized by a decrease in $A \beta_{42}$ concentration in the CSF $[9,25]$. Likewise, we reported previously that CSF $A \beta_{42}$ decreases with age in cognitively normal adults across the life span (ages 21-88), with reductions in CSF $A \beta_{42}$ becoming apparent at earlier ages for $A P O E$ - $\varepsilon 4$ carriers than $\varepsilon 4$ noncarriers [26]. This is consistent with the report of low CSF $A \beta_{42}$ and continuous decline in middle-aged $A P O E-\varepsilon 4$ carriers [27], as well as the well-established link between $A P O E$ $\varepsilon 4$ and an increased risk of $\beta$-amyloidosis [9, 28, 29].

The present study extends these findings by demonstrating more complex three-way interactions of age $x$ gender $x$ $A P O E$ genotype and different patterns of age-related change of CSF A $\beta_{42}$ in female versus male carriers of $A P O E$ $\varepsilon 4$. Male $A P O E-\varepsilon 4$ carriers exhibited modest average decline in CSF $\mathrm{A} \beta_{42}$ concentrations across participant age, whereas female $A P O E$ - $\varepsilon 4$ carriers exhibited a steeper average decline in CSF $\mathrm{A} \beta_{42}$ concentration with increasing participant age starting around age 50, coincident with the onset of menopause. Whether female $A P O E$ - $\varepsilon 4$ carriers become more vulnerable to $\mathrm{AD}$ after the onset of menopause should be investigated further. By contrast, in female $A P O E-\varepsilon 4$ noncarriers, CSF $\mathrm{A} \beta_{42}$ levels did not drop around age 50 and, instead, steadily increased over the life span. It is plausible that brain amyloidosis increases with aging; although no studies have investigated this in humans, a recent study of brain $A \beta_{42}$ in rhesus monkeys demonstrates that $\mathrm{A} \beta_{42}$ increases with aging in both brain and CSF [30]. It is also possible that the observed age-related changes are partly due to age-related alterations in the clearance of $\mathrm{A} \beta_{42}$ in brain or age-related changes in CSF flow. Because our current study uses a cross-sectional design, future studies that employ a longitudinal design will be necessary to clarify the nature of age-related $A \beta_{42}$ metabolism in the brain.

Gender differences in the brain aging and disease processes of $\mathrm{AD}$ are not well understood, and the existing literature in this area is inconsistent $[8,28,31,32]$. Using the Alzheimer's Disease Neuroimaging Initiative (ADNI) dataset, Altman et al. [32] reported that average levels of CSF total tau and tau $/ \mathrm{A} \beta_{42}$ ratio in participants with mild cognitive impairment (MCI) were higher in female $A P O E-\varepsilon 4$ carriers than male $A P O E-\varepsilon 4$ carriers; but in cognitively normal controls, they found no gender difference in either CSF $\mathrm{A} \beta_{42}$ or total-tau concentration, regardless of $A P O E$ genotype. Consistent with the findings in the normal controls, a later analysis of the ADNI dataset showed no modifying effects of APOE $\times$ gender on CSF biomarkers, but this analysis reports a significant interactive effect of $A P O E \varepsilon 4 \times$ gender on brain metabolism and structure, in that female $A P O E-\varepsilon 4$ carriers had greater hypometabolism and atrophy than female $\varepsilon 4$ noncarriers or male $\varepsilon 4$ carriers [33]. However, a study by Jack et al. [28] of neuroimaging biomarkers in cognitively normal controls who were over the age of 60 showed that men had poorer memory and smaller hippocampal volume than women; they also found that memory 
and hippocampal volume decline began at earlier ages than brain $\mathrm{A} \beta$ deposition. The authors speculated that this earlier decline in hippocampal volume may be due to cerebrovascular disease and age-related tauopathy. Our findings of a higher mean CSF concentration of vascular biomarkers in men compared to women, especially in E-selectin from age 50 to 70 , but no gender differences in total tau or p-tau ${ }_{181}$ suggest that the reduction in hippocampal volume observed in the Jack et al. study may be the result of cerebrovascular disease rather than age-related tauopathy. This is consistent with the expectation that men are at higher risk for cerebrovascular disease than women, especially in middle age and early old age [4].

There is increasing evidence that small-vessel brain disease, especially when characterized by microinfarcts, plays an important role in the cognitive health of older persons $[34,35]$, particularly older persons with hypertension and diabetes mellitus [36, 37]. Serum E-selectin, an endothelial-leukocyte adhesion molecule, plays an important role in inflammation. It is elevated in metabolic syndrome $[14,38]$, in overweight women with additional cardiovascular risk factors [38], in persons with diabetes mellitus who have silent cerebral ischemic infarcts [14], and in diabetes mellitus patients in whom these cerebral ischemic lesions have progressed further [13]. Serum E-selectin is also linked to cerebral microbleeds [39]. In our earlier study, CSF Eselectin was found to be highly correlated with BMI and diabetes mellitus in persons with a diagnosis of $\mathrm{AD}$; it was also elevated in clinically diagnosed $\mathrm{AD}$ patients who had no AD CSF biomarker signature [11]. In the present study, the correlation between CSF E-selectin and BMI, as well as the elevation in concentration of CSF VCAM1 in cognitively normal participants with diabetes mellitus, suggests that CSF E-selectin and VCAM1 may be biomarkers for cerebrovascular injuries in the brain. CSF E-selectin and the VCAM1 concentration in CSF were correlated modestly, but their relationship to age and gender were somewhat different. That is, VCAM1 increased with participant age in both genders, although males had higher mean VCAM1 levels than females across the age span of 50-100 years. In contrast, E-selectin did not increase with participant age, but males did have higher mean E-selectin levels than females aged between 50 and 70 years. Neuroimaging and/or autopsy studies are necessary to determine whether these two potential vascular biomarkers indicate different pathological processes in the development of cerebrovascular disease. Further studies are also necessary to determine whether elevated CSF E-selectin and VCAM1 are associated with functional impairments, especially to determine whether higher levels of E-selectin in men may explain their poor cognitive performance as observed in studies by Jack et al. [28] and our earlier study [15]. Such studies would also help to explain recent observations of weaker associations between cognitive function or hippocampal volume and CSF AD biomarkers of $A \beta_{42}$ and tau in men than in women [40], because cognitive impairments in men may be due in part to vascular damage that has been underestimated.

Our study has a few limitations that may affect the interpretation of the results. First, because this is a crosssectional study, our observations of age-related change are based on adults of different ages examined at a single time point rather than over time. The lower average concentration in the women with APOE $\varepsilon 4$ after age 50 may reflect a high proportion of preclinical AD cases with lower CSF $A \beta_{42}$ concentration rather than the age-related decline. The age-related longitudinal changes in CSF concentration of $\mathrm{A} \beta_{42}$, total tau, and $\mathrm{p}-\mathrm{tau}_{181}$ in individual male and female adults may differ from those exhibited by a sample of adults of different ages who were measured cross-sectionally. Although a longitudinal study of these changes would be optimal, a study that spans 80 years, from age 20 to age 100, is not feasible. Second, the differences in CSF $A \beta_{42}$ change across age by gender and $A P O E$ genotype were accompanied by relatively large variability due to the stratification of our sample into gender and $A P O E$ genotype subgroups. Confirmation of these findings in a larger sample should be carried out. Finally, we were unable to measure both $\mathrm{AD}$ and vascular biomarkers in the same cohort, and the cohort for our vascular biomarker study included only middleaged and older participants. Because the effects of gender and $A P O E$ genotype on each biomarker are age dependent, a study that includes younger participants may yield different findings from the age and gender differences in Eselectin and VCAM1 observed in the current study. Thus, further study is needed of these biomarkers across the entire adult age span. Despite these limitations, this is one of the first studies of cognitively normal adults to demonstrate age-related gender differences in both CSF AD and vascular biomarkers across a large age span with an interactive effect of $A P O E$ genotype.

\section{Conclusions}

The AD pathophysiologic process over the adult life span is complex, and brain $\beta$-amyloidosis is dependent on age, gender, and $A P O E$ genotype. Female $\varepsilon 4$ carriers appear at higher risk for $\mathrm{AD}$ after menopause, whereas men may experience a relatively higher rate of cerebrovascular injury, especially in middle and early old age, which may contribute to poorer cognitive performance.

\section{Additional file}

Additional file 1: Tables S1 and S2. Table S1 presents participant characteristics and Table $\mathbf{S 2}$ presents mean change in CSF A $\beta_{42}$ by increase in age and stratified by gender and $A P O E$ genotype predicted from linear regression of $C S F A \beta_{42}$ on the three way age $\times$ gender $\times A P O E$ genotype interaction. (DOCX $14 \mathrm{~kb})$ 


\section{Abbreviations}

AD: Alzheimer's disease; ADNI: Alzheimer's Disease Neuroimaging Initiative; ADRC: Alzheimer's Disease Research Center; APOE: Apolipoprotein E; $A \beta_{42}$ : Amyloid beta 42; BMI: Body mass index; Cl: Confidence interval; CSF: Cerebrospinal fluid; MCl: Mild cognitive impairment; p-tau ${ }_{181}$ : Phosphotau-181; VCAM1: Vascular cell adhesion protein 1

\section{Acknowledgements}

Not applicable.

\section{Funding}

This work was supported by the National Institute of Health (AG05136, AG023185, AG033693, AGO5131, and AG08017), the Royalty Research Fund, an anonymous foundation, and the Nancy and Buster Alvord Endowment at the UW. This material is also the result of work supported with resources and the use of facilities at the VA Puget Sound Health Care System. None of the funding organizations or sponsors were involved in the design and conduct of the study; collection, management analysis, and interpretation of the data; and preparation, review, or approval of the manuscript.

\section{Availability of data and materials}

The datasets analyzed during the current study are available from the corresponding author on reasonable request.

\section{Authors' contributions}

GL designed the study and drafted the manuscript. JBS performed the analysis and provided data interpretation. ECP made a major contribution to drafting the manuscript, interpreting data and providing critical review. CEY performed genotyping of $A P O E$, interpreted the data and provided critical review of the manuscript. CWW made a major contribution to interpretation of the data, especially regarding sex endocrine changes, and critical review of manuscript. DPF made a major contribution to interpretation of the data, especially regarding age-related and gender-related changes in metabolism and vascular risk factors, and provided critical review of the manuscript. AS-D contributed to the interpretation and presentation of data, particularly through drafting and critically revising the manuscript. JZ performed measurement of CSF vascular biomarkers and provided interpretation of the data. TJM performed measurement of CSF AD biomarkers and provided interpretation of the data and critical review of the manuscript. MAR obtained funding, and provided administrative support, interpretation of the data and critical review of the manuscript. JFQ recruited study subjects, collected CSF and provided interpretation of the data and critical review of the manuscript. DRG obtained major funding, recruited study subjects, collected CSF, and provided interpretation of the data and critical review of the manuscript. ERP obtained major funding, recruited study subjects, collected CSF, and provided interpretation of the data and critical review of the manuscript. All authors read and approved the final manuscript.

\section{Authors' information}

Not applicable.

\section{Competing interests}

DRG is Editor-in-Chief of Alzheimer's Research and Therapy. All other authors declare that they have no competing interests.

\section{Consent for publication}

\section{Not applicable.}

\section{Ethics approval and consent to participate}

The collection and analysis of CSF AD biomarkers and clinical data in the first cohort was approved by the UW IRB (under approval numbers 01-8926-V and 01173). The collection and analysis of novel vascular biomarkers in the second cohort occurred at UW, UCSD, and OHSU under the approval of their respective IRBs (UW 01-8926-V and 01173, UCSD 080012, and OHSU 6845). All participants provided written informed consent prior to enrollment into the study.

\section{Publisher's Note}

Springer Nature remains neutral with regard to jurisdictional claims in published maps and institutional affiliations.

\section{Author details}

'Geriatric Research, Education, and Clinical Center, VA Puget Sound Health Care System, 1660 S. Columbian Way, Seattle, WA 98108, USA. ²Department of Psychiatry and Behavioral Sciences, University of Washington, 1959 NE Pacific St, Box 356560, Seattle, WA 98195, USA. ${ }^{3}$ Northwest Network (VISN-20) Mental Illness Research, Education, and Clinical Center (MIRECC), VA Puget Sound Health Care System, 1660 S. Columbian Way, Seattle, WA 98108, USA. ${ }^{4}$ BSR\&D Program, VA Puget Sound Health Care System, 1660 S. Columbian Way, Seattle, WA 98108, USA. ${ }^{5}$ Department of Pathology, University of Washington School of Medicine, 1959 NE Pacific St, Box 357470, Seattle, WA 98195, USA. ${ }^{6}$ Department of Pathology, Stanford University, 300 Pasteur Drive, Lane 235, Stanford, CA 94305, USA. 'Parkinson's Disease Research, Education, and Clinical Care Center, Portland VA Medical Center, 3710 SW Veterans Hospital Rd, Portland, OR 97239, USA. 'Department of Neurology, Oregon Health and Science University, 3181 SW Sam Jackson Park Rd, L226, Portland, OR 97239, USA. ${ }^{9}$ Department of Neurosciences, University of California at San Diego, 9500 Gilman Drive, La Jolla, CA 92093, USA.

Received: 16 March 2017 Accepted: 31 May 2017

Published online: 03 July 2017

\section{References}

1. Andersen K, Launer LJ, Dewey ME, Letenneur L, Ott A, Copeland JR, Dartigues JF, Kragh-Sorensen P, Baldereschi M, Brayne C, et al. Gender differences in the incidence of $A D$ and vascular dementia: The EURODEM Studies. EURODEM Incidence Research Group. Neurol. 1999;53:1992-7.

2. Miech RA, Breitner JC, Zandi PP, Khachaturian AS, Anthony JC, Mayer L. Incidence of $\mathrm{AD}$ may decline in the early 90 s for men, later for women: The Cache County study. Neurology. 2002;58:209-18.

3. Kukull WA, Higdon R, Bowen JD, McCormick WC, Teri L, Schellenberg GD, van Belle G, Jolley L, Larson EB. Dementia and Alzheimer disease incidence: a prospective cohort study. Arch Neurol. 2002;59:1737-46.

4. Chene G, Beiser A, Au R, Preis SR, Wolf PA, Dufouil C, Seshadri S. Gender and incidence of dementia in the Framingham Heart Study from mid-adult life. Alzheimers Dement. 2015;11:310-20.

5. Henderson WW. Estrogen, cognition, and a woman's risk of Alzheimer's disease. Am J Med. 1997;103:11S-8S.

6. Zandi PP, Carlson MC, Plassman BL, Welsh-Bohmer KA, Mayer LS, Steffens DC, Breitner JC. Hormone replacement therapy and incidence of Alzheimer disease in older women: the Cache County Study. JAMA. 2002;288:2123-9.

7. Li G, Sokal I, Quinn JF, Leverenz JB, Brodey M, Schellenberg GD, Kaye JA, Raskind MA, Zhang J, Peskind ER, Montine TJ. CSF tau/Abeta42 ratio for increased risk of mild cognitive impairment: a follow-up study. Neurology. 2007;69:631-9.

8. Fagan AM, Roe CM, Xiong C, Mintun MA, Morris JC, Holtzman DM. Cerebrospinal fluid tau/beta-amyloid(42) ratio as a prediction of cognitive decline in nondemented older adults. Arch Neurol. 2007;64:343-9.

9. Fagan AM, Mintun MA, Mach RH, Lee SY, Dence CS, Shah AR, LaRossa GN, Spinner ML, Klunk WE, Mathis CA, et al. Inverse relation between in vivo amyloid imaging load and cerebrospinal fluid Abeta42 in humans. Ann Neurol. 2006;59:512-9.

10. Fleisher AS, Chen K, Quiroz YT, Jakimovich LJ, Gutierrez Gomez M, Langois CM, Langbaum JB, Roontiva A, Thiyyagura P, Lee W, et al. Associations between biomarkers and age in the presenilin 1 E280A autosomal dominant Alzheimer disease kindred: a cross-sectional study. JAMA Neurol. 2015;72:316-24

11. Li G, Xiong K, Korff A, Pan C, Quinn J, Galasko D, Liu C, Montine TJ, Peskind E, Zhang J. Increased CSF E-selectin in clinical Alzheimer's disease without altered CSF Abeta 42 and Tau. J Alzheimers Dis. 2015;47:883-7 in press.

12. Ewers M, Mielke MM, Hampel H. Blood-based biomarkers of microvascular pathology in Alzheimer's disease. Exp Gerontol. 2010;45:75-9.

13. Kawamura $T$, Umemura $T$, Kanai $A$, Nagashima M, Nakamura $N$, Uno $T$, Nakayama M, Sano T, Hamada Y, Nakamura J, Hotta N. Soluble adhesion molecules and $\mathrm{C}$-reactive protein in the progression of silent cerebral infarction in patients with type 2 diabetes mellitus. Metabolism. 2006;55:461-6.

14. Kawamura T, Umemura T, Kanai A, Uno T, Matsumae H, Sano T, Sakamoto N, Sakakibara T, Nakamura J, Hotta N. The incidence and characteristics of silent cerebral infarction in elderly diabetic patients: association with serumsoluble adhesion molecules. Diabetologia. 1998;41:911-7.

15. Li G, Millard SP, Peskind ER, Zhang J, Yu CE, Leverenz JB, Mayer C, Shofer JS, Raskind MA, Quinn JF, et al. Cross-sectional and longitudinal relationships between cerebrospinal fluid biomarkers and cognitive function in people 
without cognitive impairment from across the adult life span. JAMA Neurol. 2014;71:742-51.

16. Peskind ER, Riekse R, Quinn JF, Kaye J, Clark CM, Farlow MR, Decarli C, Chabal C, Vavrek D, Raskind MA, Galasko D. Safety and acceptability of the research lumbar puncture. Alzheimer Dis Assoc Disord. 2005;19:220-5.

17. Mattsson N, Andreasson U, Persson S, Arai H, Batish SD, Bernardini S, Bocchio-Chiavetto L, Blankenstein MA, Carrillo MC, Chalbot S, et al. The Alzheimer's Association external quality control program for cerebrospinal fluid biomarkers. Alzheimers Dement. 2011;7:386-95. e386.

18. Pan C, Korff A, Galasko D, Ginghina C, Peskind E, Li G, Quinn J, Montine TJ, Cain K, Shi M, Zhang J. Diagnostic values of cerebrospinal fluid T-Tau and Abeta42 using meso scale discovery assays for Alzheimer's disease. J Alzheimers Dis. 2015;45:709-19.

19. Hixson JE, Vernier DT. Restriction isotyping of human apolipoprotein $E$ by gene amplification and cleavage with Hhal. J Lipid Res. 1990;31:545-8,

20. Harrell FEJ. Regression modeling stratigies with applications to linear models, logistic regression and survival analysis. New York: Springer; 2001.

21. Davison AC, Hinkley DV. Bootstrap methods and their applications. Cambridge: Cambridge University Press; 1997.

22. Team RC. R: a language and environment for statistical computing. $R$ Foundation for Statistical Computing: Vienna; 2012

23. Harrell Jr F. rms: Regression modeling strategies. In R package, 36-0 edition. R Foundation for Statistical Computing: Vienna; 2012.

24. Canty A, Ripley B. boot: Bootstrap R (S-Plus) functions. In R package, 13-13 edition. R Foundation for Statistical Computing: Vienna; 2014

25. Vlassenko AG, McCue L, Jasielec MS, Su Y, Gordon BA, Xiong C, Holtzman DM, Benzinger TL, Morris JC, Fagan AM. Imaging and cerebrospinal fluid biomarkers in early preclinical alzheimer disease. Ann Neurol. 2016;80:379-87.

26. Peskind ER, Li G, Shofer J, Quinn JF, Kaye JA, Clark CM, Farlow MR, DeCarli C, Raskind MA, Schellenberg GD, et al. Age and apolipoprotein $\mathrm{E}^{*} 4$ allele effects on cerebrospinal fluid beta-amyloid 42 in adults with normal cognition. Arch Neurol. 2006;63:936-9.

27. Sutphen $C L$, Jasielec MS, Shah AR, Macy EM, Xiong C, Vlassenko AG, Benzinger TL, Stoops EE, Vanderstichele HM, Brix B, et al. Longitudinal cerebrospinal fluid biomarker changes in preclinical Alzheimer disease during middle age. JAMA Neurol. 2015;72(9):1029-42.

28. Jack Jr CR, Wiste HJ, Weigand SD, Knopman DS, Vemuri P, Mielke MM, Lowe V, Senjem ML, Gunter JL, Machulda MM, et al. Age, sex, and APOE epsilon4 effects on memory, brain structure, and beta-amyloid across the adult life span. JAMA Neurol. 2015;72:511-9.

29. Resnick SM, Bilgel M, Moghekar A, An Y, Cai Q, Wang MC, Thambisetty M, Prince JL, Zhou Y, Soldan A, et al. Changes in Abeta biomarkers and associations with APOE genotype in 2 longitudinal cohorts. Neurobiol Aging. 2015;36:2333-9.

30. Zhao Q, Lu J, Yao Z, Wang S, Zhu L, Wang J, Chen B. Upregulation of Abeta42 in the brain and bodily fluids of rhesus monkeys with aging. J Mol Neurosci. 2017;61:79-87.

31. Kauwe JS, Jacquart S, Chakraverty S, Wang J, Mayo K, Fagan AM, Holtzman DM, Morris JC, Goate AM. Extreme cerebrospinal fluid amyloid beta levels identify family with late-onset Alzheimer's disease presenilin 1 mutation. Ann Neurol. 2007;61:446-53.

32. Altmann A, Tian L, Henderson WW, Greicius MD. Alzheimer's Disease Neuroimaging Initiative I: sex modifies the APOE-related risk of developing Alzheimer disease. Ann Neurol. 2014;75:563-73.

33. Sampedro F, Vilaplana E, de Leon MJ, Alcolea D, Pegueroles J, Montal V, Carmona-Iragui M, Sala I, Sanchez-Saudinos MB, Anton-Aguirre S, et al. APOE-by-sex interactions on brain structure and metabolism in healthy elderly controls. Oncotarget. 2015;6:26663-74.

34. Sonnen JA, Larson EB, Haneuse S, Woltjer R, Li G, Crane PK, Craft S, Montine TJ. Neuropathology in the adult changes in thought study: a review. J Alzheimers Dis. 2009;18:703-11.

35. White L, Petrovitch H, Hardman J, Nelson J, Davis DG, Ross GW, Masaki K, Launer L, Markesbery WR. Cerebrovascular pathology and dementia in autopsied Honolulu-Asia Aging Study participants. Ann N Y Acad Sci. 2002;977:9-23.

36. Wang LY, Larson EB, Sonnen JA, Shofer JB, McCormick W, Bowen JD, Montine TJ, Li G. Blood pressure and brain injury in older adults: findings from a community-based autopsy study. J Am Geriatr Soc. 2009:57:1975-81.

37. Sonnen JA, Larson EB, Brickell K, Crane PK, Woltjer R, Montine TJ, Craft S. Different patterns of cerebral injury in dementia with or without diabetes. Arch Neurol. 2009;66:315-22.
38. Wildman RP, Kaplan R, Manson JE, Rajkovic A, Connelly SA, Mackey RH, Tinker LF, Curb JD, Eaton CB, Wassertheil-Smoller S. Body size phenotypes and inflammation in the Women's Health Initiative Observational Study. Obesity (Silver Spring). 2011:19:1482-91.

39. Huang Z, Yin Q, Sun W, Zhu W, Li Y, Liu W, Xiao L, Duan Z, Cai Q, Liu D, et al. Microbleeds in ischemic stroke are associated with lower serum adiponectin and higher soluble E-selectin levels. J Neurol Sci. 2013;334:83-7.

40. Koran ME, Wagener M, Hohman TJ, Alzheimer's NI. Sex differences in the association between AD biomarkers and cognitive decline. Brain Imaging Behav. 2016;11(1):205-13.

\section{Submit your next manuscript to BioMed Central and we will help you at every step:}

- We accept pre-submission inquiries

- Our selector tool helps you to find the most relevant journal

- We provide round the clock customer support

- Convenient online submission

- Thorough peer review

- Inclusion in PubMed and all major indexing services

- Maximum visibility for your research

Submit your manuscript at www.biomedcentral.com/submit
Biomed Central 